\title{
Results of Intralesional Bleomycin Sclerotherapy for Treatment of Orbital Lymphangiomas at a Tertiary Eye Care Centre in Bangladesh
}

\author{
Murtuza Nuruddin ${ }^{\mathrm{a}}$ Soma Rani Roy ${ }^{\mathrm{a}}$ Hardeep Singh Mudhar ${ }^{\mathrm{b}}$ \\ ${ }^{a}$ Eye Infirmary and Training Complex, Chittagong, Bangladesh; ${ }^{b}$ Department of Histopathology, Royal Hallamshire \\ Hospital, Sheffield, UK
}

\section{Keywords}

Bleomycin · Lymphangioma · Vascular malformation

\begin{abstract}
Purpose: The purpose of our study was to evaluate the role of intralesional bleomycin injection for the treatment of orbital lymphangiomas. Methods: This was a prospective interventional case study. Twelve patients diagnosed with orbital lymphangiomas received intralesional bleomycin injection at a dose of $0.5 \mathrm{mg} / \mathrm{kg}$ body weight (maximum $15 \mathrm{mg}$ ) along with lignocaine $2 \%$. Those who required retreatment were injected at intervals of 4 weeks. The outcome was reviewed radiologically and using serial photographic comparison. Result: Proptosis and lid swelling were the most frequent presentations. The number of injections ranged from 1 to 3 . Fifty percent of our patients showed complete resolution, and the other $50 \%$ showed more than $70 \%$ resolution as evidenced radiologically and on digital photography. Conclusion: No significant ophthalmic or systemic side effect was noticed in our study group. Therefore, intralesional bleomycin injection can be considered as first-line therapy for treatment of orbital lymphangiomas.

(c) 2019 S. Karger AG, Basel
\end{abstract}

(c) 2019 S. Karger AG, Basel

\section{KARGER}

E-Mail karger@karger.com

www.karger.com/oop

\section{Introduction}

The International Society for the Study of Vascular Anomalies (ISSVA) has classified lymphangiomas as combined vascular malformations within the spectrum of arterial, venous and lymphatic lesions that have characteristics of venous and lymphatic components [1-4]. These lesions within the orbit may be superficial, deep or diffuse. They may enlarge slowly or remain clinically silent, unless sudden engorgement due to intralesional haemorrhage occurs, producing a mass effect leading to globe displacement, strabismus and compressive optic neuropathy $[4,5]$. The mainstay of therapy is surgical excision, but due to diffuse infiltration within the orbit, total excision is not always possible. Extensive surgery may also cause iatrogenic damage to vital structures within the orbit. Other modalities of treatment, such as radiotherapy, and intralesional and/or oral corticosteroids are also available, but often with unsuccessful outcomes $[6,7]$. Recently, sclerosing agents like bleomycin have been used for treatment of lymphangiomas with positive outcomes [8-15]. In the present study, we have evaluated the role of intralesional bleomycin injection for the treatment of orbital lymphangiomas. 
Table 1. Demographic, clinical and treatment profile of patients

\begin{tabular}{|c|c|c|c|c|c|c|c|}
\hline $\begin{array}{l}\text { Case } \\
\text { No. }\end{array}$ & $\begin{array}{l}\text { Age, } \\
\text { years }\end{array}$ & Sex & Laterality & Presenting feature & $\begin{array}{l}\text { Injection, } \\
n\end{array}$ & $\begin{array}{l}\text { Cumulative } \\
\text { dose, IU }\end{array}$ & Complication \\
\hline 1 & 14 & M & Right & Proptosis & 3 & 45 & Mild aggravation of proptosis \\
\hline 3 & 18 & $\mathrm{~F}$ & Left & $\begin{array}{l}\text { Lid swelling and conjunctival lesion at } \\
\text { caruncular region }\end{array}$ & 2 & 30 & Lid oedema \\
\hline 4 & 14 & $\mathrm{~F}$ & Left & Proptosis with esotropia & 1 & 15 & Orbital cellulitis \\
\hline 6 & 17 & $\mathrm{M}$ & Left & Lower lid swelling & 1 & 15 & None \\
\hline 7 & 28 & $\mathrm{M}$ & Right & Lower lid and medial canthal swelling & 2 & 30 & Lid oedema \\
\hline 8 & 30 & M & Right & Sudden proptosis & 3 & 45 & Mild aggravation of proptosis \\
\hline 9 & 19 & $\mathrm{M}$ & Left & Proptosis with esotropia & 3 & 30 & Mild aggravation of proptosis \\
\hline 10 & 22 & $\mathrm{~F}$ & Left & Lid swelling & 2 & 45 & None \\
\hline
\end{tabular}

\section{Materials and Methods}

This prospective study was conducted at the Orbit and Oculoplastic Clinic of Chittagong Eye Infirmary and Training Complex (CEITC) from July 2015 to June 2017. It was approved by the institutional ethical committee.

Twelve patients with orbital lymphangiomas diagnosed clinically, radiologically and/or histologically were included in the study. Exclusion criteria included bleomycin sensitivity, patients lost to follow-up, impaired renal or pulmonary function, pregnancy and lactation. Informed written consent was obtained from patients or patients' guardians.

All patients underwent physical and ophthalmologic examination, including visual acuity, refraction, anterior and posterior segment assessment. Computed tomography of the orbit was carried out in all patients. Diagnosis was based on clinical and radiological evidence, and histopathological confirmation was done in all patients except two.

Bleomycin is commercially available in dried powder form in vials containing 15 international unit (IU) of bleomycin. 1 IU of bleomycin is equivalent to $1 \mathrm{mg}$ of bleomycin. The dose of bleomycin for treatment of orbital lymphangiomas was calculated as $0.5 \mathrm{mg} / \mathrm{kg}$ body weight, but the maximum dose did not exceed 15 mg. Bleomycin solution was prepared with normal saline and $2 \%$ lignocaine at the ratio of $1: 1$. The injected volume was calculated to be equivalent to the volume of the lesion but did not exceed $4 \mathrm{~mL}$ at 1 session. The prepared solution was injected within the lesion using a 23-gauge needle. Multiple punctures were often required. Care was taken to keep the needle outside the muscle cone, and soon after injection, local pressure was applied to prevent leakage of bleomycin. The fluid of the lymphangiomas was drained, if any was present, before injecting bleomycin. Post-injection oral steroid ( $1 \mathrm{mg} / \mathrm{kg}$ body weight per day) was prescribed for a week. Pupillary reactions were monitored for a couple of hours following injection. Patients were reviewed on the first day postoperatively and again at 2 weeks. Those who required retreatment were injected at intervals of 4 weeks.

Treatment was discontinued after a maximum of 3 injections or when no further sign of resolution was noticed clinically. Computed tomography (CT) scan of the orbits was repeated 3 months after the last injection to document the radiological evidence, and the final outcome was noted. Patients remained under follow-up up to 6 months after completion of the treatment course.

\section{Results}

A total of 12 patients were included in the study, of which 5 were male and 7 were female. Four patients were in the paediatric group $(<16$ years of age). All patients presented with unilateral presentation. Proptosis was the most frequent presenting feature (56\%), followed by lid swelling (44\%). Two patients with lid swelling also had associated conjunctival swelling. Two patients with proptosis had associated esotropia. Table 1 summarizes the demographic, clinical and treatment profiles of the patients.

All patients underwent CT scan of the orbits to ascertain the diagnosis and to determine the extent of the lesion. Eight patients had histopathological confirmation of the diagnosis prior to treatment with injection of bleomycin. The number of bleomycin injections ranged from 1 to 3 . Only 3 patients (25\%) required 3 injections for optimum outcome, and the rest of the patients (75\%) required 1 or 2 treatments for satisfactory outcome. Only 2 

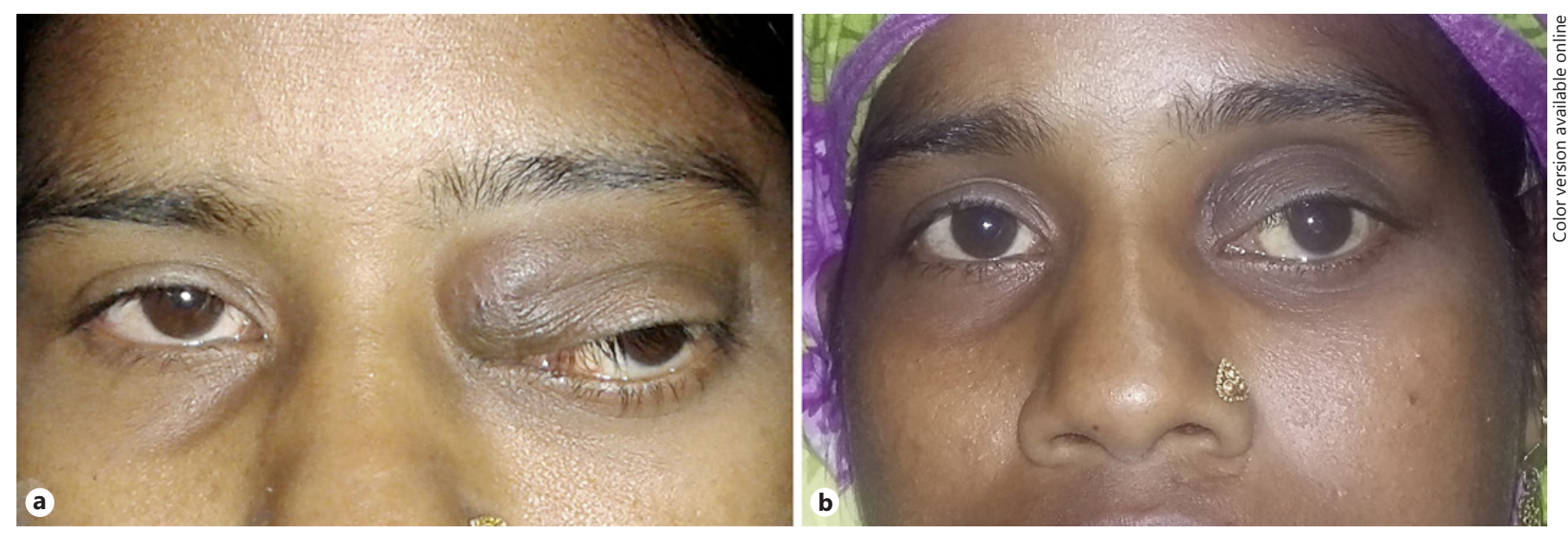

Fig. 1. a, b This patient had a history of debulking surgery followed by recurrence. The lesion resolved, and the globe returned to its primary position after intralesional bleomycin injection therapy.

patients underwent cystic fluid aspiration prior to injection of bleomycin, and both of these patients required a single treatment for complete resolution. One patient had a history of debulking surgery and recurrence after 3 years. She showed significant improvement after a single treatment, though she required 3 injections for complete resolution (Fig. 1). Six of our patients (50\%) showed complete resolution, and the other 50\% showed more than $70 \%$ resolution, as evidenced radiologically (Fig. 2) and with serial photographic comparison (Fig. 3, 4).

Immediate side effects of intralesional bleomycin injection observed in our study included eyelid oedema and transient increase in proptosis. One of our patients presented with orbital cellulitis 3 days after bleomycin injection, and 1 patient presented with diffuse subconjunctival haemorrhage. There were no systemic complications related to bleomycin encountered in our study.

\section{Discussion}

Orbital lymphangiomas are benign orbital lesions producing a myriad of symptoms. They often impose an increased risk for the development of amblyopia, strabismus and compressive optic neuropathy [4]. Sudden intralesional haemorrhage may result in acute painful proptosis and may also threaten the vision. The management of orbital lymphangiomas is difficult, and surgery remains the mainstay of treatment. Because of the diffuse and infiltrative nature of the lesion, it is often impossible to excise the lesion in toto. Therefore, other modalities of treatment, particularly use of sclerosing agents, have been tried with variable outcomes [8-15].

Bleomycin is a sclerosing agent. In 1966, Umezawa [16] first isolated bleomycin as an anti-tumour, anti-viral and anti-bacterial agent. This was first isolated from the soil fungus Streptomyces verticillus. The main biochemical action of bleomycin is inhibition of DNA synthesis. It has also a sclerosing effect on the vascular endothelium, which has been described in treating vascular anomalies [16]. Systemic use of bleomycin has been approved by the FDA for various conditions, like squamous cell carcinoma of the head and neck, cervix, penis and skin, Hodgkin's and non-Hodgkin's lymphoma, testicular malignant tumours and other malignancies.

The solution of bleomycin is prepared by addition of lignocaine $2 \%$ along with normal saline at the ratio of $1: 1$. The presence of lignocaine in the solution reduces discomfort for the patient postoperatively and also facilitates the entry of bleomycin into the cell by making the cellular membranes more permeable.

A literature review reveals very few articles on the use of bleomycin in vascular anomalies. Mathur et al. [11] used bleomycin as a sclerosing agent for congenital lymphatic and vascular malformations of the head and neck, where the sclerosing effect was of value in causing regression. Gooding and Meyer [8] described bleomycin as a potential treatment for refractory orbital lymphangiomas, showing satisfactory outcome in 4 cases. Kumar et al. [10] had a satisfactory response in 95\% of non-orbital lymphangiomas treated with bleomycin. Rozman et al. [9] achieved satisfactory outcomes of intralesional bleo- 

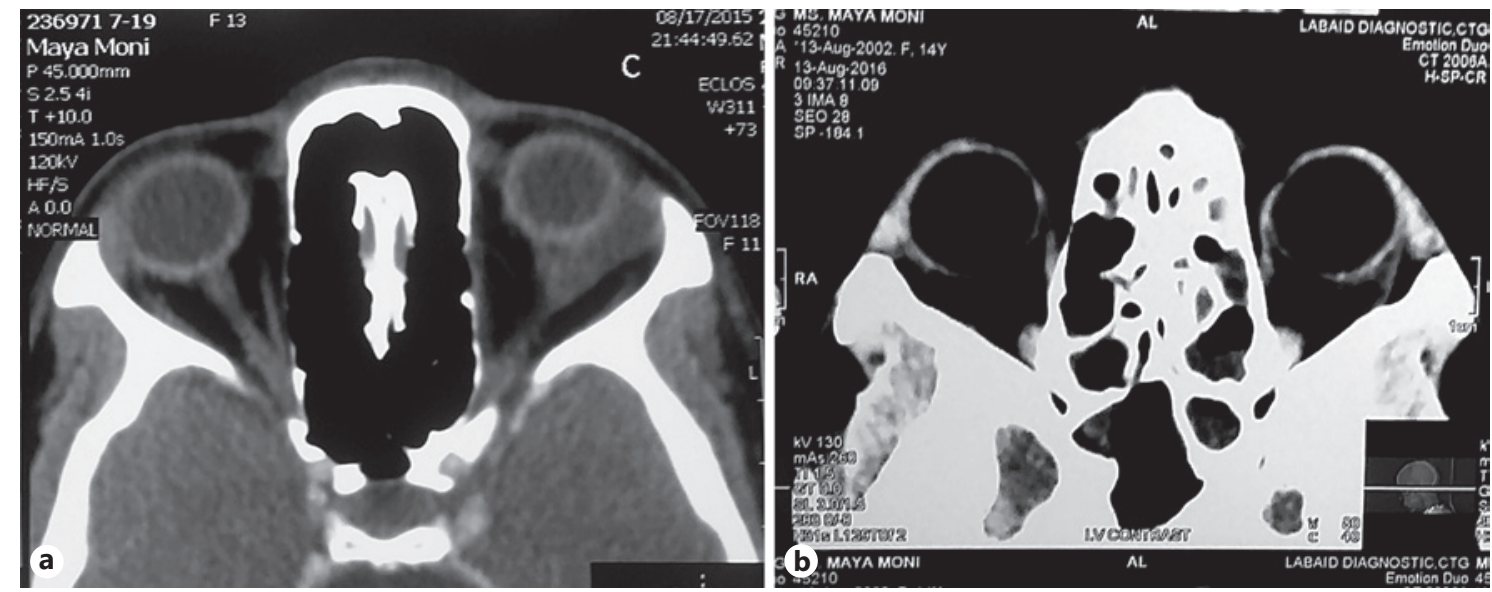

Fig. 2. a, b Computed tomography scan of pre- and post-injection of bleomycin. The lesion has almost disappeared.
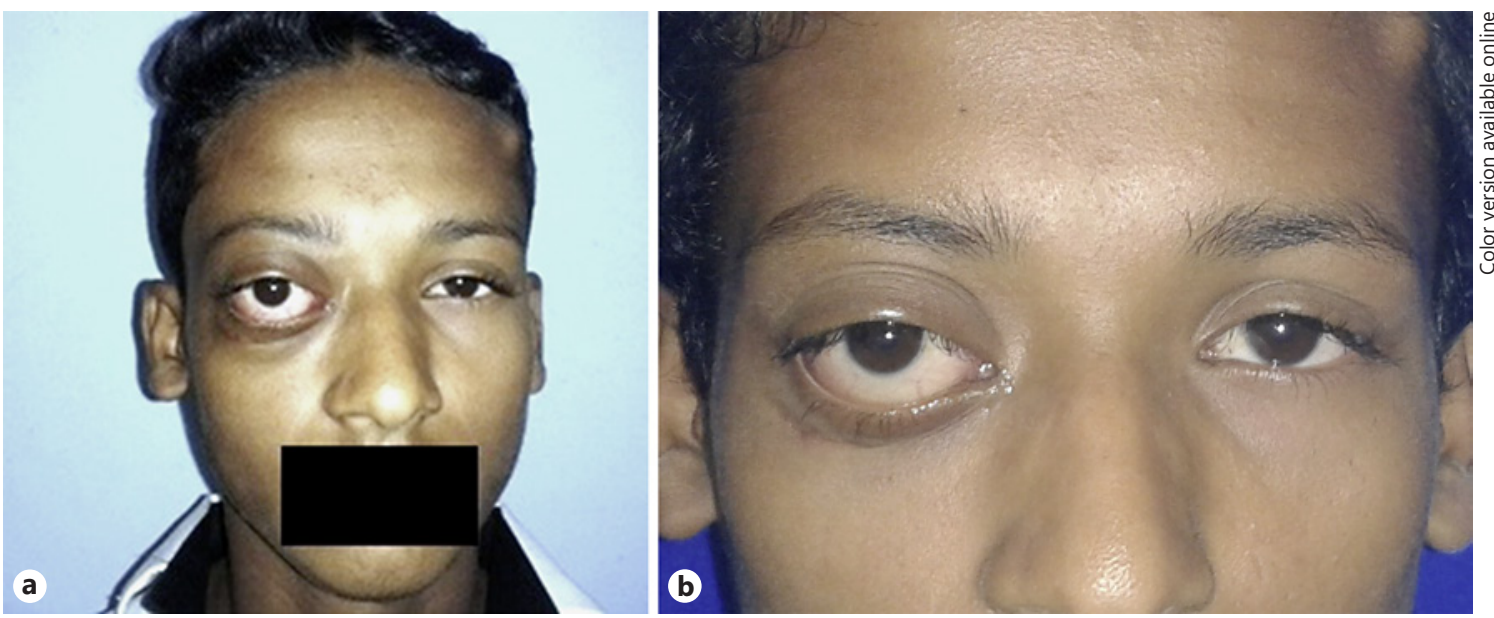

Fig. 3. a, b Pre- and post-injection pictures of a patient receiving bleomycin. Proptosis has markedly decreased. Exophthalmometry reading has been reduced from 29 to $20 \mathrm{~mm}$.

mycin sclerotherapy in managing lymphangiomas of the face, neck and thorax region. Raichura et al. [15] reported a dramatic response in 13 patients with orbital lymphangioma who were treated with intralesional bleomycin injection. Other modalities of treatment for management of lymphangioma have been reported with variable outcomes. Barnacle et al. [17] reported satisfactory resolution of orbital lymphangioma with intralesional sodium tetradecyl sulphate. Hill et al. [18] treated microcystic lesions with intralesional sodium tetradecyl sulphate and ethanol, while treating macrocystic lesions with injected doxycycline. A promising role of oral sildenafil has also been reported for treatment of lymphangiomas $[19,20]$.

There is no proper guideline regarding the number of doses required for bleomycin injections for orbitallymphangiomas. Raichura et al. [15] treated their patients with 1-6 doses of bleomycin injection. Among our patients, 3 patients received 3 doses, 5 patients received 2 doses, and the other 4 patients received a single dose to achieve satisfactory outcome. If no improvement is observed with 2 subsequent injections, then treatment may be discontinued. Common side effects related to intralesional bleo- 

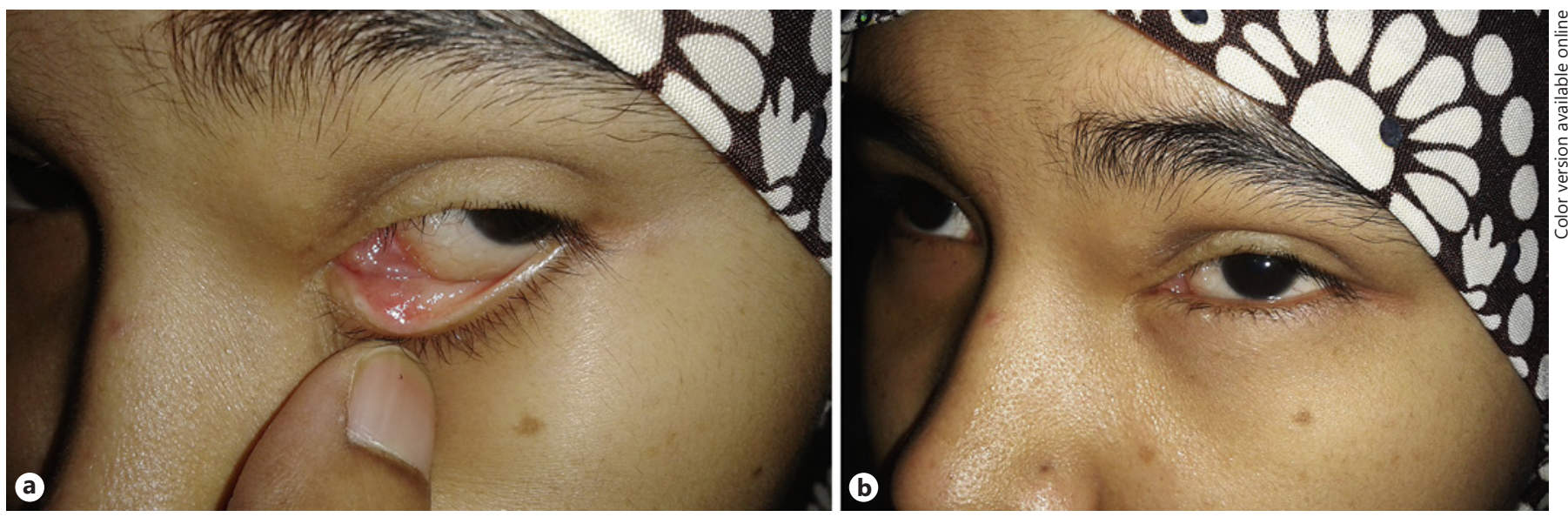

Fig. 4. a, b Disappearance of conjunctival lesion after bleomycin injection. Redness is markedly reduced.

mycin sclerotherapy include pain, erythema, swelling and occasionally fever. Local skin necrosis and eschar formation may also occur at the site of injection [9-11]. We prescribed systemic steroids ( $1 \mathrm{mg} / \mathrm{kg}$ body weight) for 1 week in all our cases to attempt to reduce inflammation related to bleomycin therapy. Pulmonary fibrosis has also been associated with intravenous bleomycin administration, but no such report has been attributed to intralesional bleomycin sclerotherapy.

All our patients remained under follow-up for a minimum period of 6 months, and we observed no recurrence during this period. Zhong et al. [21] reported a series of 200 patients with head and neck lymphangiomas treated with intralesional bleomycin injection. They showed a cure rate of $86.5 \%$ with no recurrence in 2 years of followup. Paramasivam et al. [22] treated 16 patients with orbital lymphangiomas with intralesional bleomycin injection and reported a volume reduction between $50 \%$ and $80 \%$ in all cases. They found no recurrence, although the follow-up period was short, ranging from 6 weeks to 6 months. Raichura et al. [15] reported a dramatic response in 13 patients with orbital lymphangiomas treated with intralesional bleomycin and observed no recurrence during their follow-up period ranging from 7 to 26 months. All these observations refer to the fact that there is a minimal chance of recurrence of lymphangiomas following treatment with intralesional bleomycin injection. However, a longer follow-up in a large case series is necessary to establish this fact.

To conclude, intralesional bleomycin sclerotherapy is an effective treatment modality for orbital lymphangiomas. No long-standing ophthalmic side effects nor any systemic side effects were noted in our case series. Therefore, intralesional bleomycin can be considered as a safe first-line agent for the treatment of orbital lymphangiomas.

\section{Statement of Ethics}

The patients/parents gave their informed consent for publication of this article (text and photographs). The study protocol was approved by the institute's committee on human research. The study involved no animal experimentation.

\section{Disclosure Statement}

This study did not attract specific sponsorship or funding. There are no conflicts of interest.

\footnotetext{
References

1 International Society for the Study of Vascular Anomalies [Internet]. Classification of Vascular Anomalies [cited 2016 April 18]. Available from: issva.org/classification.

2 Rootman J, Hay E, Graeb D, Miller R. Orbitaladnexal lymphangiomas. A spectrum of hemodynamically isolated vascular hamartomas. Ophthalmology. 1986 Dec;93(12):1558-70.

3 Holds JB. The spectrum of orbital vascular disease. Int Ophthalmol Clin. 1992;32(3):59-72.

4 Graeb DA, Rootman J, Robertson WD, Lapointe JS, Nugent RA, Hay EJ. Orbital lymphangiomas: clinical, radiologic, and pathologic characteristics. Radiology. 1990 May;175(2):417-21.
} 
5 Jones IS. Lymphangiomas of the ocular adnexa. An analysis of sixty-two cases. Am J Ophthalmol. 1961 Mar;51(3):481-509.

6 Wilson ME, Parker PL, Chavis RM. Conservative management of childhood orbital lymphangioma. Ophthalmology. 1989 Apr; 96(4):484-9.

7 Waner M, Suen JY. Treatment options for the management of vascular malformations. In: Waner M, Suen JY, editors. Hemangiomas and vascular malformations of the head and neck. New York: Wiley-Liss; 1999. pp. 315-50.

8 Gooding C, Meyer D. Intralesional bleomycin: a potential treatment for refractory orbital lymphangiomas. Ophthalmic Plast Reconstr Surg. 2014 May-Jun;30(3):e65-7.

9 Rozman Z, Thambidorai RR, Zaleha AM, Zakaria Z, Zulfiqar MA. Lymphangioma: is intralesional bleomycin sclerotherapy effective? Biomed Imaging Interv J. 2011 Jul-Sep; 7(3):e18.

10 Kumar V, Kumar P, Pandey A, Gupta DK, Shukla RC, Sharma SP, et al. Intralesional bleomycin in lymphangioma: an effective and safe non-operative modality of treatment. J Cutan Aesthet Surg. 2012 Apr;5(2):133-6.
11 Mathur NN, Rana I, Bothra R, Dhawan R, Kathuria G, Pradhan T. Bleomycin sclerotherapy in congenital lymphatic and vascular malformations of head and neck. Int J Pediatr Otorhinolaryngol. 2005 Jan;69(1):75-80.

12 Baskin D, Tander B, Bankaoğlu M. Local bleomycin injection in the treatment of lymphangioma. Eur J Pediatr Surg. 2005 Dec; 15(6):383-6.

13 Mahajan JK, Bharathi V, Chowdhary SK, Samujh R, Menon P, Rao KL. Bleomycin as intralesional sclerosant for cystic hygromas. J Indian Assoc Pediatr Surg. 2004;9(1):3-7.

14 Giguère CM, Bauman NM, Smith RJ. New treatment options for lymphangioma in infants and children. Ann Otol Rhinol Laryngol. 2002 Dec;111(12 Pt 1):1066-75.

15 Raichura ND, Alam MS, Noronha VO, Mukherjee B. A prospective study of the role of intralesional bleomycin in orbital lymphangioma. J AAPOS. 2017 Apr;21(2):146-51.

16 Umezawa H. Recent study on biochemistry and action of Bleomycin. In: Carter SK, Crook ST, Umezawa H, editors. Bleomycin: Current Status and New Developments. New York (NY): Academic Press; 1978. pp. 15-20.
17 Barnacle AM, Theodorou M, Maling SJ, Abou-Rayyah Y. Sclerotherapy treatment of orbital lymphatic malformations: a large single-centre experience. Br J Ophthalmol. 2016 Feb;100(2):204-8.

18 Hill RH 3rd, Shiels WE 2nd, Foster JA, Czyz CN, Stacey A, Everman KR, et al. Percutaneous drainage and ablation as first line therapy for macrocystic and microcystic orbital lymphatic malformations. Ophthal Plast Reconstr Surg. 2012 Mar-Apr;28(2):119-25.

19 Swetman GL, Berk DR, Vasanawala SS, Feinstein JA, Lane AT, Bruckner AL. Sildenafil for severe lymphatic malformations. N Engl J Med. 2012 Jan;366(4):384-6.

20 Danial C, Tichy AL, Tariq U, Swetman GL, Khuu P, Leung TH, et al. An open-label study to evaluate sildenafil for the treatment of lymphatic malformations. J Am Acad Dermatol. 2014 Jun;70(6):1050-7.

21 Zhong PQ, Zhi FX, Li R, Xue JL, Shu GY. Long-term results of intratumorous bleomycin-A5 injection for head and neck lymphangioma. Oral Surg Oral Med Oral Pathol Oral Radiol Endod. 1998 Aug;86(2):139-44.

22 Paramasivam S, Fay A, Fifi J, Berenstein A. O-015 image guided bleomycin sclerotherapy for orbital lymphatic malformation. J Neuro Intervent Surg. 2014;6 Suppl 1:A8-9. 